\title{
PCL/PHBV Microparticles as Innovative Carriers for Oral Controlled Release of Manidipine Dihydrochloride
}

\author{
Fernanda Malaquias Barboza, ${ }^{1}$ Willian Moreira Machado, ${ }^{2}$ \\ Luiz Renato Olchanheski Junior, ${ }^{2}$ Josiane Padilha de Paula, ${ }^{1}$ Sônia Faria Zawadzki, ${ }^{3}$ \\ Daniel Fernandes, ${ }^{2}$ and Paulo Vitor Farago ${ }^{1}$
}

\author{
${ }^{1}$ Laboratory of Pharmaceutical Products, Postgraduate Program in Pharmaceutical Science, Department of Pharmaceutical Sciences, \\ State University of Ponta Grossa, 4748 Carlos Cavalcanti Avenue, 84030-900 Ponta Grossa, PR, Brazil \\ ${ }^{2}$ Laboratory of Cardiovascular Pharmacology, Postgraduate Program in Pharmaceutical Science, \\ Department of Pharmaceutical Sciences, State University of Ponta Grossa, 4748 Carlos Cavalcanti Avenue, \\ 84030-900 Ponta Grossa, PR, Brazil \\ ${ }^{3}$ Laboratory of Synthetic Polymers, Postgraduate Program in Chemistry, Department of Chemistry, Federal University of Paraná, \\ Centro Politécnico Jardim das Américas, P.O. Box 19081, 81531-990 Curitiba, PR, Brazil
}

Correspondence should be addressed to Paulo Vitor Farago; pvfarago@gmail.com

Received 30 August 2013; Accepted 28 October 2013; Published 16 January 2014

Academic Editors: G. Marucci and M. Ozyazici

Copyright ( 2014 Fernanda Malaquias Barboza et al. This is an open access article distributed under the Creative Commons Attribution License, which permits unrestricted use, distribution, and reproduction in any medium, provided the original work is properly cited.

\begin{abstract}
Microparticles of poly( $\varepsilon$-caprolactone) (PCL) and poly(3-hydroxybutyrate-co-3-hydroxyvalerate) (PHBV) containing manidipine dihydrochloride (MAN) were successfully prepared by the simple emulsion/solvent evaporation method. All formulations showed loading efficiency rates greater than $80 \%$ and average particle size less than $8 \mu \mathrm{m}$. Formulations had spherical shape with smooth and porous surface for PCL and PHBV, respectively. According to Fourier-transform infrared spectroscopy, initial components were not chemically modified during microencapsulation. X-ray diffraction patterns and differential scanning calorimetry demonstrated that this process led to drug amorphization. In vitro dissolution studies showed that all microparticles prolonged MAN release, mainly which one obtained using PCL that contained 5\% of drug loaded (PCL-M5). Animal studies demonstrated that formulation $P C L-M 5$ was able to keep the variation of mean arterial pressure after phenylephrine administration up to 24 hours. These data confirmed the sustained antihypertensive effect of the investigated microparticles. Results provided an experimental basis for using formulation PCL-M5 as a feasible carrier for oral controlled release of MAN intended for treating high blood pressure.
\end{abstract}

\section{Introduction}

The primary goal of the treatment of hypertensive patients is to achieve the maximum decrease in the long-term total risk of cardiovascular and renal morbidity and mortality. In addition to the lowering of blood pressure, a successful drug also requires appropriate pharmacological properties in order to avoid comorbidities $[1,2]$.

Among several antihypertensive drugs, calcium channel blocks are widely used due to their efficacy, tolerability, and safety. In this group, manidipine, 2-[4-(diphenylmethyl)1-piperazinyl] ethylmethyl $( \pm)$-1, 4-dihydro-2, 6-dimethyl4-(m-nitrophenyl)-3, 5-pyridinedicarboxylate (Figure 1), stands out as a third-generation calcium channel blocker, effective for treating high blood pressure even to elderly people or patients with associated diseases such as diabetes and nephropathy [3-5].

In particular, it presents high tolerability which results in a low frequency of adverse events. Several studies have reported that manidipine has a low oedematogenic potential when compared to other dihydropyridines and it is not associated with increased heart rate. Furthermore, this drug does not appear to activate the sympathetic nervous system [6]. In addition to reducing arterial blood pressure, manidipine has been related to metabolic effects of potential clinical interest. It blocks T-type calcium channels present in the efferent 


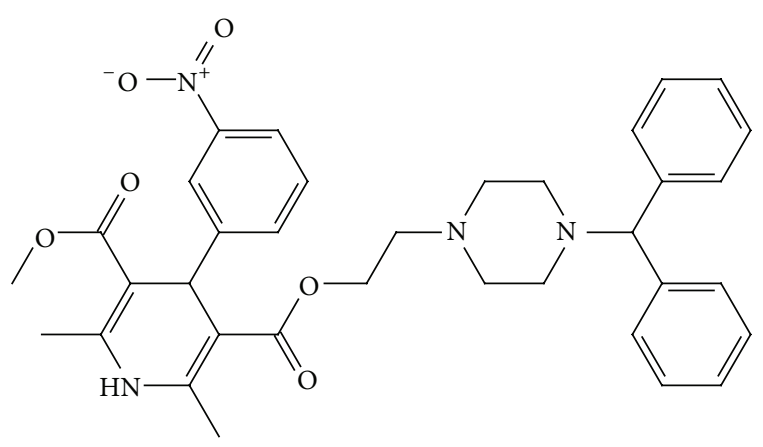

FIGURE 1: Chemical structure of manidipine.

glomerular arterioles that can decrease intraglomerular pressure and microalbuminuria [2].

As other dihydropyridine derivatives, manidipine exhibits high clearance and first pass metabolism and hence a low systemic bioavailability. Moreover, after oral administration, it presents a peak plasma concentration after 1-2 $\mathrm{h}$ with an apparent elimination half-life of 4-8 h [7].

In spite of the fact that manidipine presents a short elimination half-life, its high lipophilicity makes it being rapidly removed from circulation to adipose tissue. Manidipine is then continuously released from fat cells which promotes a time of action up to 24 hours [4]. This spontaneous compartmentalization becomes a complicating factor for drug therapy, since drug release is dependent on the mass of adipose tissue of the patient, which is very changeable in population. Therefore, manidipine demonstrates a sustained but heterogeneous and individualized release profile.

Thus, a further improvement is necessary to attain a substantial advance in absorption and bioavailability of manidipine $[7,8]$. In that sense, the development of new formulations useful for controlling manidipine release along gastrointestinal tract and enhancing drug therapy [9] is required.

Considering this purpose, microencapsulation is able to avoid its fast compartmentalization in adipose cells, besides showing high efficiency over controlling drug delivery and protecting drug degradation by physiological metabolism and adverse environmental conditions [10-15].

Few studies describe delivery systems for manidipine. Papers are only devoted to describe manidipine complexation using cyclodextrin and its derivatives $[7,8]$. The literature does not report works involving manidipine-loaded polymeric microparticles. Thus, the aim of this study was to obtain poly( $\varepsilon$-caprolactone) (PCL) and poly(3-hydroxybutyrate-co3-hydroxyvalerate) (PHBV) microparticles containing manidipine dihydrochloride. These polyesters are attractive materials for controlled-release drug applications due to their biocompatibility and biodegradability since their decomposition products are not toxic. Manidipine dihydrochloride-loaded PCL/PHBV microparticles were also characterized and in vitro and in vivo studies were carried out in order to explore their potential as oral drug delivery carriers intended for treating high blood pressure.

\section{Materials and Methods}

2.1. Materials. Manidipine dihydrochloride (MAN) (Zi Bo Riyuexin Chemical Industrial, Shandong, China), poly( $\varepsilon$ caprolactone) (PCL) $\left(M_{w}=70,000-90,000 \mathrm{~g} \cdot \mathrm{mol}^{-1}\right.$, SigmaAldrich, St. Louis, MO, USA), poly(3-hidroxybutirate-co-3hydroxyvalerate) (PHBV) $\left(M_{w}=380,000 \mathrm{~g} \cdot \mathrm{mol}^{-1}, 8.70 \mathrm{~mol} \%\right.$ hydroxyvalerate, Biocycle L110, PHB Industrial, Serrana, Brazil), polysorbate 80 (Sigma-Aldrich, St. Louis, MO, USA), and poly(vinyl alcohol) (PVA) $\left(M_{w}=72,000 \mathrm{~g} \cdot \mathrm{mol}^{-1}\right.$, $88.5 \mathrm{~mol} \%$ of hydrolysis, Vetec, Rio de Janeiro, Brazil) were used as received. All reagents and solvents were of analytical grade.

2.2. Preparation of PCL and PHBV Microparticles. Polymeric microparticles containing MAN were prepared by simple emulsion/solvent evaporation method. Dichloromethane and chloroform were used as organic solvent for PCL and $\mathrm{PHBV}$, respectively. The emulsion was stabilized using PVA and polysorbate 80 . Two different formulations (Table 1) were obtained for each polymer (PCL and PHBV) depending on the theoretical amount of MAN used in their composition (5 and 10\%). Unloaded microparticles were also prepared as negative controls ( $P C L-M O$ e $P H B V-M O)$. All formulations were obtained in triplicate.

In brief, the organic phase was quickly added into the aqueous phase under mechanical stirring (3500 rpm) for $5 \mathrm{~min}$. The emulsion was kept under mechanical stirring $(1000 \mathrm{rpm})$ at room temperature for $4 \mathrm{~h}$. After solvent evaporation, microparticles were separated by centrifugation (3500 rpm), washed twice with purified water, and dried at $35 \pm 5^{\circ} \mathrm{C}$ for $48 \mathrm{~h}$. All procedures were performed under dark conditions.

In order to provide a comparative analysis, physical mixtures between MAN and the chosen polyesters were also prepared using 1:1 (MAN : polymer) in weight proportion.

2.3. Determination of Loading Efficiency. The amount of drug loaded into PCL and PHBV microparticles was determined by means of a previously developed method by high performance liquid chromatography with UV detection (HPLC/UV). An amount of microparticles, equivalent to $50 \mathrm{mg}$ of MAN, was weighted and magnetic stirred with $100 \mathrm{~mL}$ of methanol for $12 \mathrm{~h}$ in order to completely extract the drug from microparticles. Samples were suitable diluted in methanol and filtered through a poly(vinylidene fluoride) membrane filter (Durapore membrane, $0.45 \mu \mathrm{m}$ pore size, Millipore, Bedford, MA, USA). The concentration of MAN was obtained chromatographically through a LiChroCart (Merck, Darmstadt, Germany) analytical column $(4 \times$ $250 \mathrm{~mm}$ ) filled with LiChrospher $100 \mathrm{RP}-18$ (5 $\mu \mathrm{m})$ with UV detection at $265 \mathrm{~nm}$ in triplicate. The mobile phase was composed of phosphate buffer $\mathrm{pH} 5.0$ and acetonitrile $(9: 1 \mathrm{v} / \mathrm{v})$ with a flow rate of $0.5 \mathrm{~mL} \cdot \mathrm{min}^{-1}$. 
TABLE 1: Composition of manidipine-loaded and unloaded PCL/PHBV microparticles.

\begin{tabular}{|c|c|c|c|c|c|c|}
\hline Formulation & $P C L-M O$ & PCL-M5 & PCL-M10 & $P H B V-M 0$ & PHBV-M5 & PHBV-M10 \\
\hline \multicolumn{7}{|l|}{ Organic } \\
\hline MAN (g) & - & 0.1 & 0.2 & - & 0.1 & 0.2 \\
\hline PCL (g) & 2.0 & 1.9 & 1.8 & - & - & - \\
\hline PHBV (g) & - & - & - & 2.0 & 1.9 & 1.8 \\
\hline Dichloromethane $(\mathrm{mL})$ & 40 & 40 & 40 & - & - & - \\
\hline Chloroform (mL) & - & - & - & 40 & 40 & 40 \\
\hline \multicolumn{7}{|l|}{ Aqueous } \\
\hline $2 \%$ PVA solution $(\mathrm{mL})$ & 200 & 200 & 200 & 200 & 200 & 200 \\
\hline Polysorbate 80 (g) & 0.25 & 0.25 & 0.25 & 0.25 & 0.25 & 0.25 \\
\hline $\mathrm{NaOH} 0.1 \mathrm{M}(\mathrm{mL})$ & 2 & 2 & 2 & - & - & - \\
\hline
\end{tabular}

The amount of manidipine was calculated and reported as loading efficiency, following (1)

Consider loading efficiency\%

$$
=\frac{\text { mass of MAN in microparticles }}{\text { theoretical mass of MAN }} \times 100 \text {. }
$$

\subsection{Characterization}

2.4.1. Analyses of Morphology and Surface. Morphology and surface data were evaluated using a scanning electron microscope (SSX-550 Superscan, Shimadzu, Kyoto, Japan). Samples were mounted on aluminum stubs, sputtered with gold (IC50 Ion Coater, Shimadzu, Kyoto, Japan). Micrographs were obtained at an accelerating voltage of $10 \mathrm{kV}$ with different magnifications.

Microparticles surface was analyzed by wide-angle Xray powder diffraction in an X-ray diffractometer (Shimadzu XRD-6000, Kyoto, Japan) in order to observe peaks related to crystalline structures [16]. Samples were scanned from a Cu$\mathrm{K} \alpha$ source $(\lambda=1.5418 \AA$ ) at $40 \mathrm{kV}$ and $30 \mathrm{~mA}$, using $2 \theta$ from $2^{\circ}$ to $80^{\circ}$ at a scan rate of $2^{\circ} \cdot \mathrm{min}^{-1}$.

2.4.2. Determination of Particle Size and Granulometric Distribution. The particle size distribution was estimated from the measurement of about 200 particles, assuming spherical shape, observed in an arbitrary chosen area in enlarged micrographs by Image Tool Software (3.0 version, San Antonio, TX, USA). Span, a mathematical value related to the granulometric dispersion, was calculated using (2):

$$
\operatorname{span}=\frac{d_{(v, 90)}-d_{(v, 10)}}{d_{(v, 50)}},
$$

where $d_{(v, 10)}, d_{(v, 50)}$, and $d_{(v, 90)}$ match, respectively, to the particles diameter at 10,50 , and $90 \%$ of the accumulated distribution of the sample.

2.4.3. Fourier-Transform Infrared Spectroscopy. Raw materials, PCL, and PHBV microparticles and physical mixtures were analyzed by Fourier-transform infrared (FTIR) spectroscopy on a Shimadzu IR Prestige-21 spectrophotometer (Kyoto, Japan). Samples were recorded from 4000 to
$400 \mathrm{~cm}^{-1}$, using $\mathrm{KBr}$ pellets filled with $1 \%$ of each sample using $64 \mathrm{scans} \cdot \mathrm{min}^{-1}$ and resolution of $2 \mathrm{~cm}^{-1}$.

2.4.4. Thermal Analyses. The thermal stability of PCL and PHBV microparticles was investigated with a TGA209 thermobalance (Netzsch-Gerätebau, Selb, Germany) using $5 \mathrm{mg}$ of sample into platinum crucibles. The thermogravimetric analyses (TGA) were held under dynamic $\mathrm{N}_{2}$ atmosphere with a flow rate of $50 \mathrm{~mL} \cdot \mathrm{min}^{-1}$. Temperature ranged from 25 to $600^{\circ} \mathrm{C}$, following a constant heating rate of $10^{\circ} \mathrm{C} \cdot \mathrm{min}^{-1}$.

Differential scanning calorimetry (DSC) curves were obtained in a DSC-60 calorimeter (Shimadzu, Kyoto, Japan) using aluminum crucibles with $5 \mathrm{mg}$ of sample, under dynamic $\mathrm{N}_{2}$ atmosphere with a flow rate of $50 \mathrm{~mL} \cdot \mathrm{min}^{-1}$. Temperature ranged from -120 a $250^{\circ} \mathrm{C}$, with a constant rate of $10^{\circ} \mathrm{C} \cdot \mathrm{min}^{-1}$, according to the particular characteristics of each material. The equipment was previously calibrated with indium (m.p. $=156.6^{\circ} \mathrm{C} ; \Delta H_{\text {melting }}=28.54 \mathrm{~J} \cdot \mathrm{g}^{-1}$ ) and zinc (m.p. $=419.6^{\circ} \mathrm{C}$ ). Thermograms provided information about thermal behavior changes of the studied materials $[16,17]$.

2.5. In Vitro Release Studies. Dissolution rates of MAN as pure drug and from polyester microparticles were carried out in a Nova Ética 299-6 ATTS dissolution tester equipped with paddles. Systems were kept at a thermostatically controlled temperature of $37 \pm 0.5^{\circ} \mathrm{C}$ and stirred at $50 \mathrm{rpm}$. The chosen dissolution medium was acetate buffer $(50 \mathrm{mM}, \mathrm{pH} 4.0$, $900 \mathrm{~mL}$ ) as recommended by The Japanese Pharmacopoeia [18]. All experiments were performed under dark conditions.

At fixed time intervals, samples were collected, filtered $(0.45 \mu \mathrm{m}$ pore size $)$ and analyzed spectrophotometrically at $228 \mathrm{~nm}$ [18]. The dissolution value was obtained from the amount of drug released. A correction factor was applied to the cumulative dilution caused by replacement of the sample with an equal volume of fresh medium.

2.5.1. Analysis of Release Behavior. In order to compare the dissolution profiles of MAN and its microparticulate systems, model-independent and model-dependent methods were performed as summarized in Table 2 .

As model-independent analysis, dissolution efficiency, the area under a dissolution curve between defined time 
TABLE 2: Mathematical models applied to dissolution experiments.

\begin{tabular}{lc}
\hline Model & Equation \\
\hline Dissolution efficiency & $\mathrm{DE}=\frac{\int_{0}^{t} y \cdot d t}{y_{100} \cdot t} \times 100 \%$ \\
First-order & $\% D=100\left(1-e^{-k t}\right)$ \\
Biexponential & $\% D=100\left[1-\left(A e^{-\alpha t}+B e^{-\beta t}\right)\right]$ \\
Zero-order & $\% D=k t$ \\
Weibull & $\% D=100\left[1-e^{-(t / \mathrm{TD}) b}\right]$ \\
Monolag & $\% D=100\left[1-e^{-k(t-x)}\right]$ \\
\hline
\end{tabular}

$\% D$ : dissolved percentage; $b$ : shape parameter; TD: time interval necessary to release $63.2 \%$ of the drug; $k$, $\alpha$, and $\beta$ : kinetics constants; $t$ : dissolution time; $A$ and $B$ : initial drug concentrations that contribute for the two dissolution stages.

points [19], was used to compare dissolution profiles. Oneway ANOVA with Tukey's post hoc test was also used to compare release rates of the pure drug and polymeric microparticles [20] by Microsoft Excel 2007 software (Salt Lake City, UT, USA). A $P$ value of $\leq 0.05$ was used to indicate statistically significant differences.

Profiles were also investigated by model-dependent approaches [21, 22] using the MicroMath Scientist 2.01 software (Salt Lake City, USA). Data were tested to fit first-order, biexponential, zero-order, weibull, and monolag equations (Table 2). For selecting the best model of MAN releasing, it was considered the correlation coefficient $(r)$, the model selection criteria (MSC), and graphical adjustment.

2.6. In Vivo Animal Studies of Antihypertensive Potential. Female Wistar rats, 90 days old, weighting between 200 and $300 \mathrm{~g}$, were housed at room temperature $\left(22 \pm 2^{\circ} \mathrm{C}\right)$ with controlled light/dark cycle, with free access to water and food. All procedures were performed in agreement with the Ethics Committee of State University of Ponta Grossa in compliance to the Guide for the Care and Use of Laboratory Animals published by the US National Institutes of Health.

2.6.1. Experimental Protocol. Ninety-six rats were randomly divided into four groups of twenty-four animals each one. Group 1 received pure MAN ( $1 \mathrm{mg} \cdot \mathrm{kg}^{-1}$, orally), group 2 received $P C L-M 5$ microparticles (amount equivalent to $1 \mathrm{mg}$ of the drug. $\mathrm{kg}^{-1}$, orally), group 3 received $P H B V-M 5$ microparticles (amount equivalent to $1 \mathrm{mg}$ of the drug. $\mathrm{kg}^{-1}$, orally), and group 4 received sterile water $(500 \mu \mathrm{L})$. At different time intervals after treatment $(1,2,6,12$, and $24 \mathrm{~h})$ animals were instrumented for blood pressure measurement, as described below. Mean blood pressure and vasoconstrictor response to phenylephrine were recorded.

2.6.2. Evaluation of Cardiovascular Parameters. Under anesthesia (ketamine, $75 \mathrm{mg} \cdot \mathrm{kg}^{-1}$, and xylazine $15 \mathrm{mg} \cdot \mathrm{kg}^{-1}$ ), polyethylene cannula (PE-50) was inserted into the left femoral vein of the rats for phenylephrine injections
TABLE 3: Loading efficiency values obtained to MAN-loaded PCL and PHBV microparticles.

\begin{tabular}{lc}
\hline Formulation & Loading efficiency $(\%) \pm \mathrm{SD}^{*}$ \\
\hline PCL-M5 & $88.99 \pm 1.46$ \\
PCL-M10 & $89.79 \pm 2.88$ \\
PHBV-M5 & $85.29 \pm 2.28$ \\
PHBV-M10 & $90.98 \pm 2.43$ \\
\hline
\end{tabular}

${ }^{*}$ SD: standard deviation.

$\left(10 \mathrm{nmol} \cdot \mathrm{kg}^{-1}\right)$. Then, the right carotid artery was isolated and a heparinized polyethylene catheter (Angiocath, number 19, $\mathrm{BD}$, Curitiba, Brazil) was inserted for measuring blood pressure. Mean arterial blood pressure $(\mathrm{mmHg})$ were recorded by integration software (Chart 7 pro, ADInstruments, Dunedin, New Zealand). Finally, rats were sacrificed using an anesthetic overdose. Statistical analysis was performed using one-way ANOVA followed by Dunnet's post hoc test. A $P$ value of $\leq 0.05$ was used to indicate statistically significant differences.

\section{Results and Discussion}

3.1. Preparation of PCL and PHBV Microparticles. Polyester microparticles were successfully obtained by the proposed simple emulsion/solvent evaporation procedure, resulting in suitable yield rates (over $80 \%$ ) for all formulations.

3.2. Determination of Loading Efficiency. Loading efficiencies obtained for PCL and PHBV microparticles using HPLC/UV method are summarized in Table 3. All formulations presented high loading rates, greater than $80 \%$. These results can be related to the low water solubility of MAN $\left(<1 \mathrm{mg} \cdot \mathrm{mL}^{-1}\right.$ at $25^{\circ} \mathrm{C}$ ) which prevents its migration to the external aqueous phase and provides high drug entrapment into the microparticles.

\subsection{Characterization}

3.3.1. Analyses of Morphology and Surface. SEM micrographs showed that PCL microparticles presented a spherical shape with a smooth and regular surface (Figures 2(a)-2(c)). PHBV microparticles also showed a spherical shape, however, with a porous surface (Figures 2(d)-2(f)). Pores were observed even on the negative control. The presence of pores represents morphological evidence that can change the drug release process from microparticles. According to the literature, pores may result from the nature of the polyhydroxyalkanoate used or from fast removal of the organic solvent [23].

$\mathrm{X}$-ray diffraction patterns are indicated in Figures 3 and 4. Different peaks related to a crystalline structure were observed either to MAN or polymers. PCL and PHBV formulations showed crystalline diffraction patterns very similar to pure polyesters. These results suggest that the microencapsulation procedure provided a remarkable decrease of the crystalline diffraction peaks of manidipine leading to drug amorphization. In general, amorphous solids dissolve more quickly than crystalline forms, due to free energies involved 


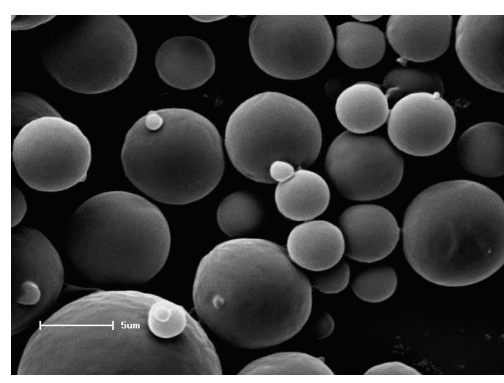

(a)

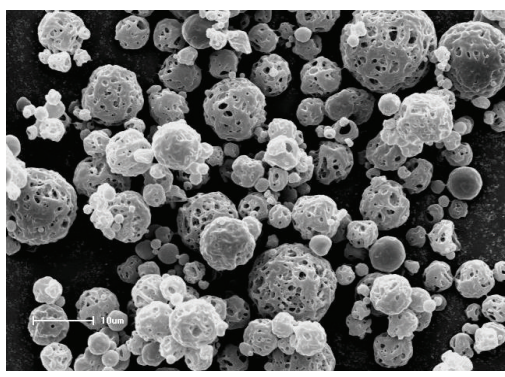

(d)

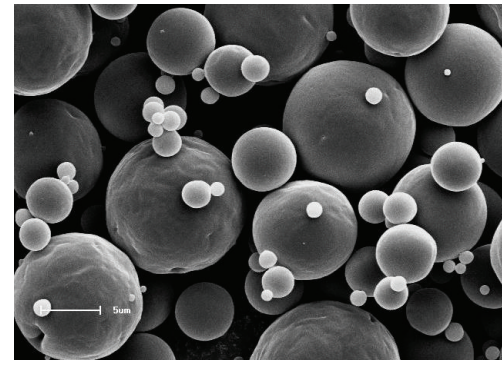

(b)

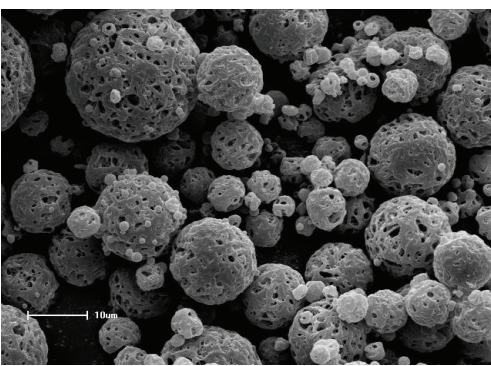

(e)

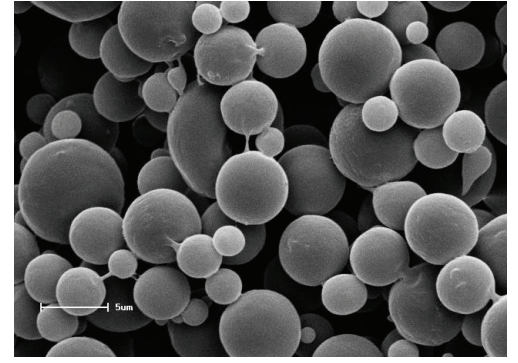

(c)

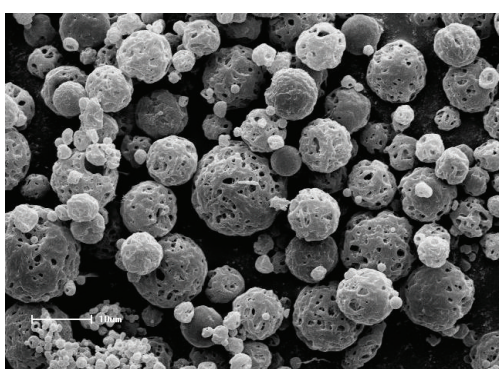

(f)

Figure 2: SEM photomicrographs of PCL and PHBV microparticles: PCL-MO (a), PCL-M5 (b), PCL-M10 (c), PHBV-MO (d), PHBV-M5 (e), and $P H B V-M 10$ (f).

in their dissolution process. Solids in amorphous state have randomly arranged molecules; thus, low energy is required to separate them what makes their dissolution faster when compared to crystalline form [24].

\subsubsection{Determination of Particle Size and Granulometric Dis-} tribution. The particle size and granulometric dispersion (span) obtained for PCL and PHBV microparticles are indicated in Table 4. All formulations presented mean diameters values under $8 \mu \mathrm{m}$. These micrometer-sized particles can provide a prolonged effect of MAN, since they present an extended intestinal transit [25].

Regarding span, most of the microparticles showed values under 2 which represent that they have a narrow dispersion around the mean particle size, suggesting a suitable unimodal behavior.

3.3.3. Fourier-Transform Infrared Spectroscopy. FTIR spectra obtained for MAN, PCL, PHBV, physical mixtures, and PCL and PHBV microparticles are shown in Figures 5 and 6.

The FTIR spectrum of pure MAN presented a typical N$\mathrm{H}$ stretching band at $3345 \mathrm{~cm}^{-1}$, ester $\mathrm{C}=\mathrm{O}$ stretching band at $1721 \mathrm{~cm}^{-1}, \mathrm{NO}_{2}$ asymmetric and symmetric stretching bands at 1534 and $1350 \mathrm{~cm}^{-1}$, aromatic $\mathrm{C}=\mathrm{C}$ stretching band at $1482 \mathrm{~cm}^{-1}, \mathrm{C}-\mathrm{N}$ stretching band at $1218 \mathrm{~cm}^{-1}$, and out-ofplane bending of aromatic $\mathrm{C}-\mathrm{H}$ bonds at 757 and $708 \mathrm{~cm}^{-1}$.

As PCL is an aliphatic polyester, its spectrum showed a strong band at $1728 \mathrm{~cm}^{-1}$, corresponding to ester $\mathrm{C}=\mathrm{O}$ stretching and two bands at 2945 and $2867 \mathrm{~cm}^{-1}$ assigned to symmetric and asymmetric $\mathrm{C}-\mathrm{H}_{2}$ stretching, respectively [26]. Similarly, PHBV spectrum exhibited a strong band at
TABLE 4: Particle size and granulometric size distribution of PCL and PHBV formulations.

\begin{tabular}{lcc}
\hline Formulation & $\begin{array}{c}\text { Average particle } \\
\text { size }(\mu \mathrm{m})\end{array}$ & Span \\
\hline PCL-M0 & 5.69 & 1.52 \\
PCL-M5 & 6.49 & 1.73 \\
PCL-M10 & 6.74 & 2.21 \\
PHBV-M0 & 6.04 & 1.17 \\
PHBV-M5 & 7.66 & 1.79 \\
PHBV-M10 & 4.10 & 1.40 \\
\hline
\end{tabular}

$1725 \mathrm{~cm}^{-1}$ due to ester $\mathrm{C}=\mathrm{O}$ stretching. Its symmetric and asymmetric -C-O-C- stretching vibration showed typical bands from 828 to $980 \mathrm{~cm}^{-1}$ and 1058 to $1134 \mathrm{~cm}^{-1}$, respectively [23].

Physical mixtures and MAN-loaded microparticles presented band assignments at the same wavenumber range of FTIR spectra and formulations did not show any new band assignment. Both polymers used have terminal primary hydroxyl groups, whereas MAN presents a reactive aromatic nitro group. Aromatic nitro compounds are usually reduced to anilines. However, during microencapsulation, there is no reducing medium to make it possible.

Therefore, it is suitable to ensure that initial components were not chemically modified, safely preserving the expected therapeutic effect of the drug.

3.3.4. Thermal Analyses. Thermogravimetric analyses (TGA) of MAN showed two events of mass loss, the first event between 166 and $203^{\circ} \mathrm{C}(\Delta m=2.99 \%)$ and the second one 


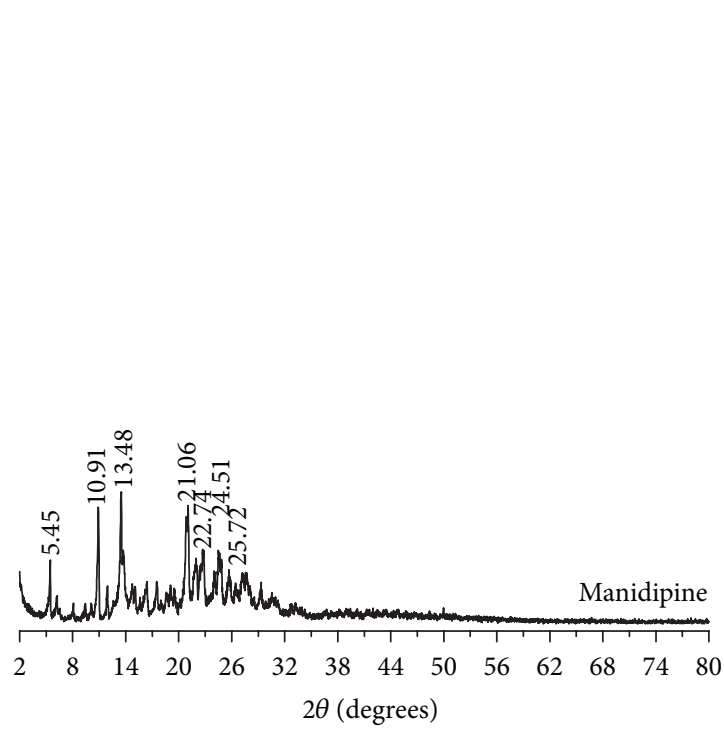

(a)

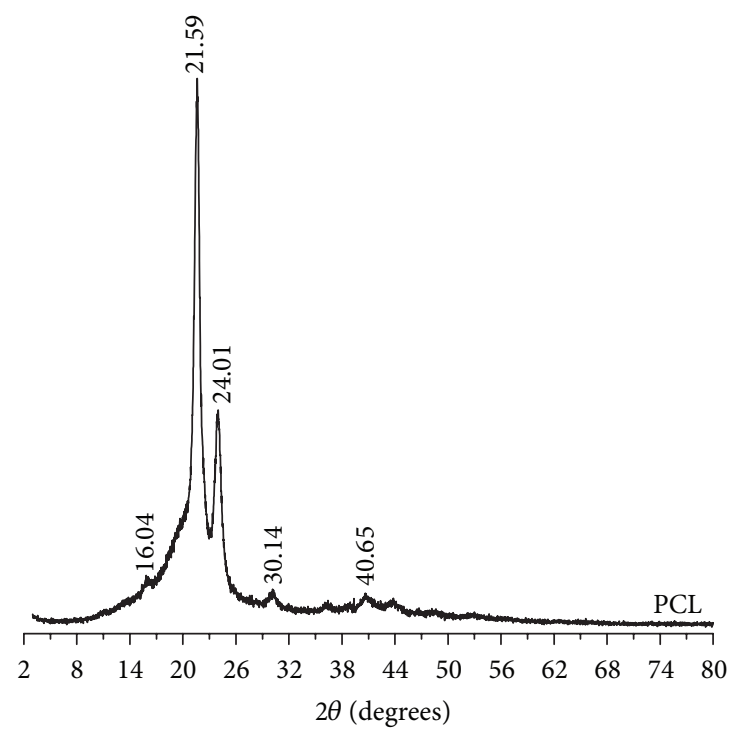

(b)

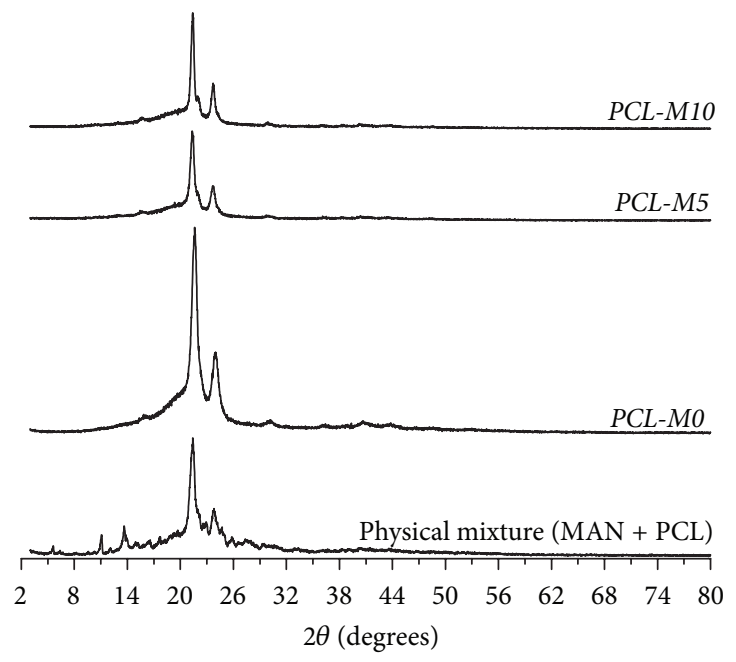

(c)

FIGURe 3: X-ray diffractions spectra of MAN, PCL, physical mixture (MAN + PCL), and PCL microparticles.

between 208 and $522^{\circ} \mathrm{C}(\Delta m=87.46 \%)$. On the other hand, TGA curves of polymers presented a single event of mass loss at the temperature range of 247 and $467^{\circ} \mathrm{C}(\Delta m=97.84 \%)$ and 224 and $291^{\circ} \mathrm{C}(\Delta m=96.91 \%)$ for PCL and PHBV, respectively.

PCL microparticles started its mass loss at $224^{\circ} \mathrm{C}$ while PHBV microparticles started it at $161^{\circ} \mathrm{C}$. These results indicate that PCL formulations are more thermally stable than PHBV formulations. Similar results have been described in the literature for PCL and PHBV microparticles [24, 27].

DSC curves demonstrated that MAN showed a sharp endothermic event at $210^{\circ} \mathrm{C}$. PCL and PHBV presented their melting temperatures at 60 and $168^{\circ} \mathrm{C}$, respectively. All PCL and PHBV microparticles had a single melting event at the same temperature observed for pure polymers and the typical melting event of MAN was not verified in DSC curves of PCL and PHBV formulations. Therefore, these results confirmed the previously obtained data from X-ray diffraction which suggested the drug amorphization.

3.4. In Vitro Release Studies. Dissolution rates of MAN and MAN-loaded microparticles are shown in Figure 7. Release profiles demonstrated that the mean time for $80 \%$ releasing of pure drug was about 2.2 hours. However, PCL microparticles presented mean dissolution times of 23.0 hours (PCL-M5) and 8.7 hours (PCL-M10) for $80 \%$ drug release. For PHBV formulations, a value of $80 \%$ drug release was achieved in mean dissolution times of 10.7 and 6.7 hours for $P H B V-M 5$ and $P H B V-M 10$, respectively. These results confirm that all formulations exhibited a prolonged release of the drug.

Formulations containing 5\% of MAN prolonged the drug release for a longer time when compared to the other ones 


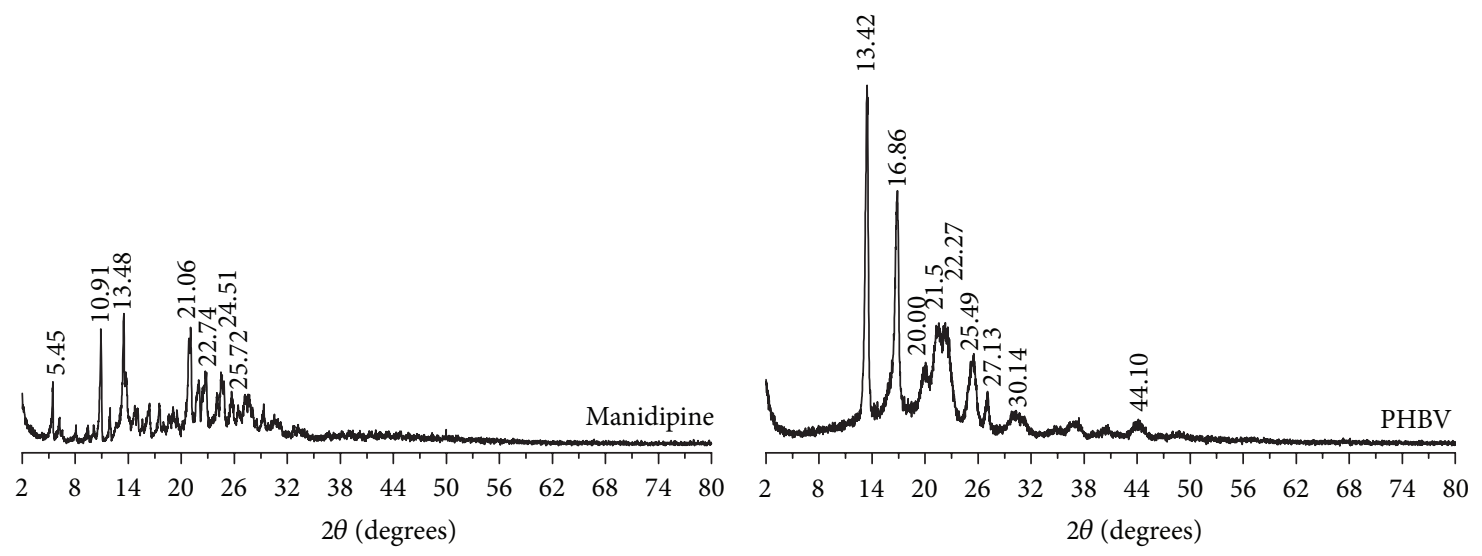

(a)

(b)
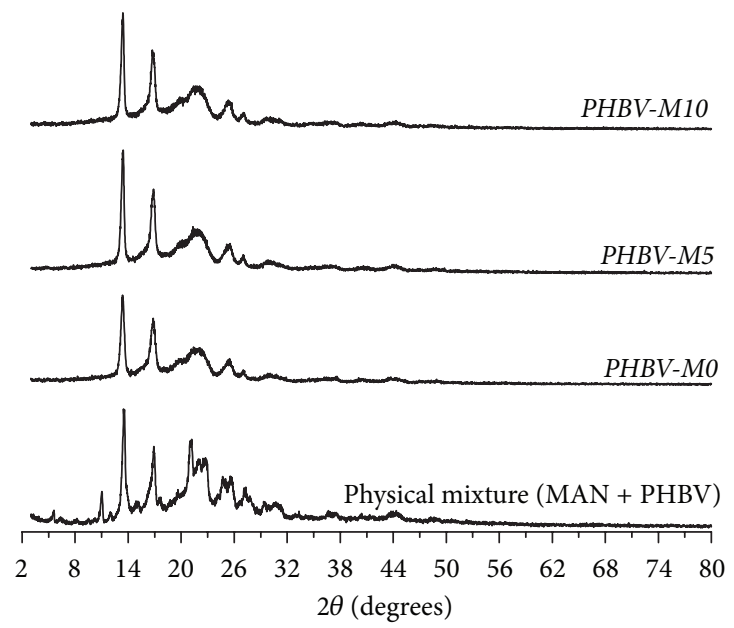

(c)

FIGURE 4: X-ray diffractions spectra of MAN, PHBV, physical mixture (MAN + PHBV), and PHBV microparticles.

with $10 \%$. This result can be justified because of the increased polymer/drug proportion into M5 formulations. In addition, the presence of pores in the surface of PHBV microparticles, as previously verified in the SEM micrographs, can make the solvent access easier and is strongly related to faster dissolution profiles. Regarding the obtained drug release profiles, PCL-M5 and PHBV-M5 were the best formulation for providing a controlled drug release and was chosen for further in vivo pharmacological evaluation.

3.4.1. Analysis of Release Behavior. Regarding dissolution efficiency (DE) data, PCL and PHBV microparticles reduced the dissolution rate, as expected for all controlled release formulations. Whereas the pure drug presented a dissolution efficiency of $73.6 \%$, along four hours, PCL and PHBV formulations showed 39.7 and $48.1 \%$ for PCL-M5 and PCL-M10, and 49.5 and $54.0 \%$ for $P H B V-M 5$ and $P H B V-M 10$, respectively.

For the aim of evaluating the difference among release profiles, the Tukey's post hoc test was performed on the results of ANOVA. This analysis indicated a statistically significant difference between pure drug and PCL-M5 $(P=0.001), P C L$ $M 10(P=0.025)$, and $P H B V-M 5(P=0.023)$. However, there
TABLE 5: Release data from MAN and MAN-loaded microparticles.

\begin{tabular}{lcccc}
\hline & \multicolumn{4}{c}{ Biexponential model } \\
& MSC & $R$ & $\alpha\left(\mathrm{h}^{-1}\right)$ & $\beta\left(\mathrm{h}^{-1}\right)$ \\
\hline MAN & 2.7983 & 0.9930 & 0.8703 & 0.7732 \\
PCL-M5 & 4.7431 & 0.9973 & 2.5659 & 0.0619 \\
PCL-M10 & 4.7644 & 0.9979 & 1.5495 & 0.1234 \\
PHBV-M5 & 4.8927 & 0.9988 & 1.8285 & 0.0959 \\
PHBV-M10 & 5.8751 & 0.9992 & 2.3060 & 0.1698 \\
\hline
\end{tabular}

was no statistical difference between MAN and PHBV-M10 $(P=0.099)$.

Release profiles were also fitted to mathematical models and the selection of the best model considered $r$, MSC, and the graphic adjustment. Both MAN and PCL and PHBV microparticles were better fitted to the biexponential equation (Table 5) than other models. The burst release apparent rate constants $(\alpha)$ and the slow release apparent rate constants $(\beta)$ are reported in Table 5.

All results demonstrated that PCL and PHBV microparticles were able for controlling MAN release, nevertheless 


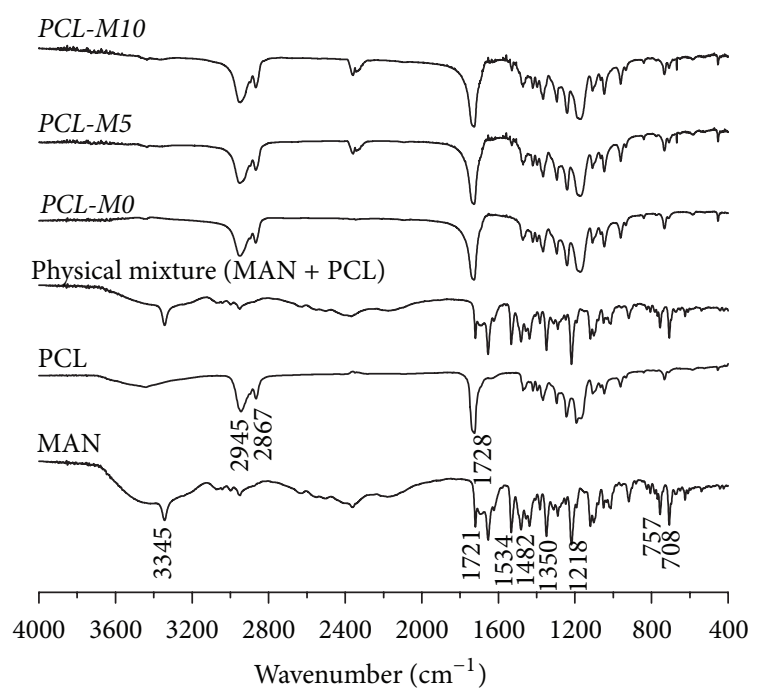

FIGURE 5: FTIR spectra of MAN, PCL, physical mixture (MAN + PCL), and PCL microparticles.

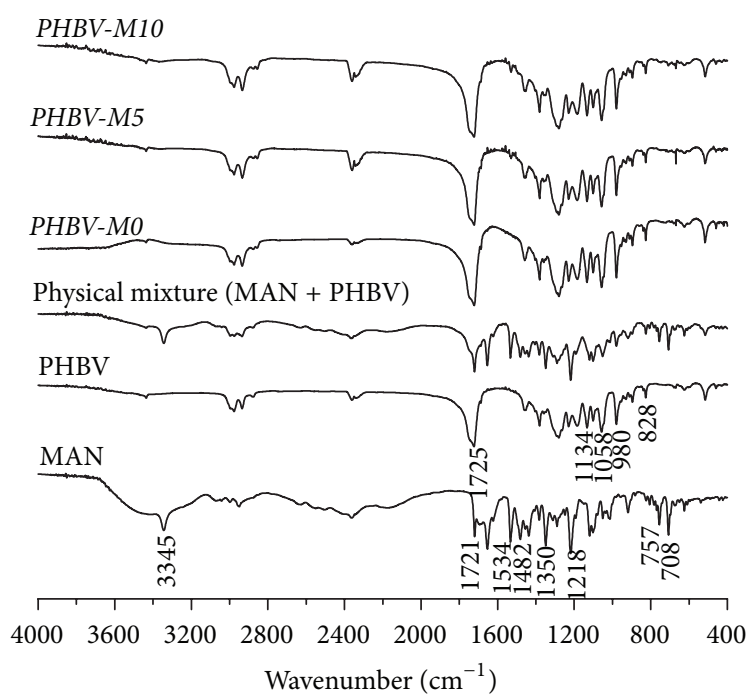

FIgURE 6: FTIR spectra of MAN, PHBV, physical mixture (MAN + $\mathrm{PHBV}$ ), and PHBV microparticles.

without changing its release model. In that sense, it is possible to predict that formulations just modified undesirable pharmacokinetic characteristics of the drug with no interference in its releasing mechanism throughout the gastrointestinal tract.

3.5. In Vivo Animal Studies of Antihypertensive Potential. Considering the previously reported results, both $P C L$ $M 5$ and $P H B V-M 5$ were chosen for further pharmacological investigation. In vivo performances of MAN-loaded microparticles over mean arterial pressure (MAP) in rats are shown in Figure 8.

For all studied times, control group showed a variation in MAP of $14.99 \mathrm{mmHg}$ forward phenylephrine administration.

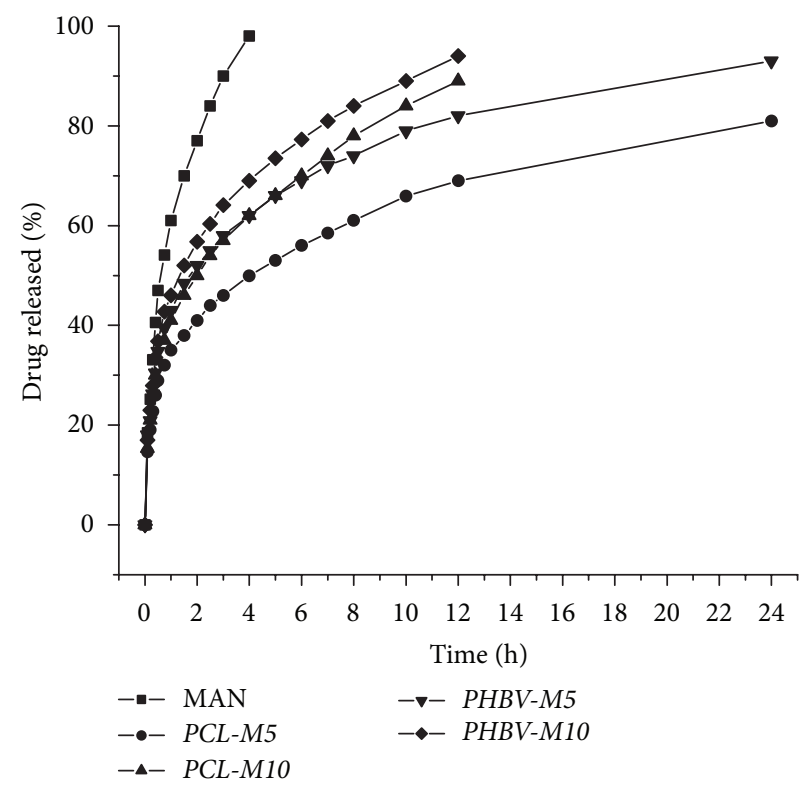

FIGURE 7: Release profiles of MAN and MAN-loaded microparticles into acetate buffer (50 mM, pH 4.0).

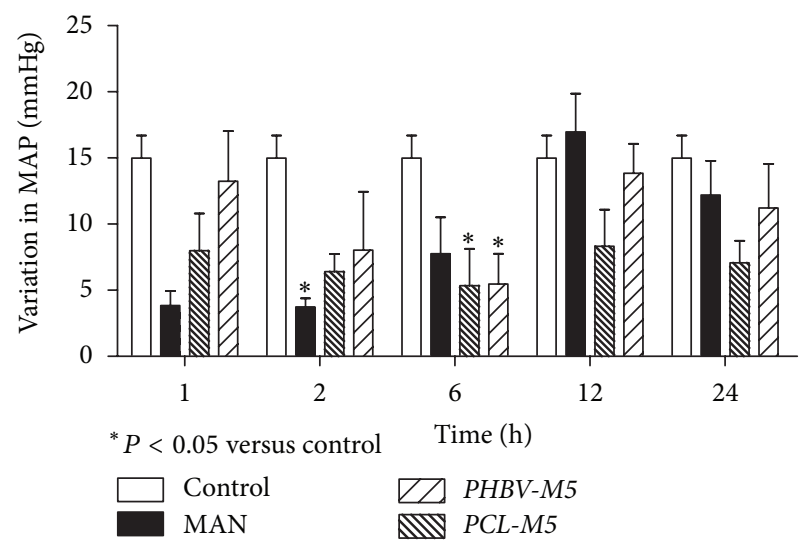

FIGURE 8: Effects of MAN on mean arterial pressure (MAP) after phenylephrine injection. Formulations PCL-M5 and PHBV-M5, pure MAN, and water (control group) were administered orally to the animals. Statistical analysis was performed using ANOVA test followed by Dunnet's post hoc test.

One, $2,6,12$, and 24 hours after phenylephrine administration, PCL-M5 formulation demonstrated changes in MAP of $7.98,6.40,5.33,8.33$, and $7.07 \mathrm{mmHg}$, respectively. $\mathrm{PHBV}-\mathrm{M} 5$ presented a variation in MAP of 13.24, 8.04, 5.46, 13.84, and $11.22 \mathrm{mmHg}$, respectively, whereas pure MAN had changes in MAP of 3.85, 3.74, 7.77, 16.97, and $12.20 \mathrm{mmHg}$, respectively. A low variation in MAP forward phenylephrine administration demonstrates that the antihypertensive drug is able to keep the basal arterial pressure under any stimulus.

Therefore, formulation PCL-M5 was able to hold down the mean arterial pressure variation up to 24 hours in contrast to that observed for the pure drug and PHBV-M5. 
These in vivo data provided an experimental basis for using formulation PCL-M5 as a feasible carrier for oral controlled release of MAN intended for treating high blood pressure.

\section{Conclusions}

The preparation of PCL and PHBV microparticles containing MAN was reported for the first time. The formulations combined suitable physicochemical characteristics and prolonged drug release. Morphological and surface data played a crucial role to explain drug release performance. Animal studies demonstrated that formulation PCL-M5 was able to hold down the variation in mean arterial pressure up to 24 hours and thereby provided a long-lasting antihypertensive effect. In summary, this formulation is a feasible carrier for controlled release of MAN and can be used into further innovative medicines intended for treating high blood pressure.

\section{Conflict of Interests}

The authors have no direct relation or financial involvement with any commercial organization with interest in the subject or materials discussed in this paper.

\section{References}

[1] R. E. Schmieder, "Cardiovascular risk management-efficacy of manidipine in hypertension and beyond," European Cardiology, vol. 4, no. 1, pp. 69-674, 2008.

[2] N. B. Rios, F. R. Esparragon, C. F. A. Rodriguez, and J. C. R. Perez, "Vascular and metabolic properties of manidipine," Nefrologia, vol. 31, pp. 268-274, 2011.

[3] R. Fogari, A. Zoppi, A. Mugellini, P. Preti, L. Corradi, and P. Lusardi, "Effect of low-dose manidipine on ambulatory blood pressure in very elderly hypertensives," Cardiovascular Drugs and Therapy, vol. 13, no. 3, pp. 243-248, 1999.

[4] O. Kohmann Jr. and A. B. Ribeiro, "Manidipina no tratamento da hipertensão arterial essencial estágio I e II do paciente com sobrepeso ou obesidade androide: estudo multicêntrico brasileiro de eficácia, tolerabilidade e efeitos metabólicos," Arquivos Brasileiros de Cardiologia, vol. 77, pp. 463-470, 2001.

[5] N. Martell-Claros and J. J. de la Cruz, "Manidipine for hypertension not controlled by dual therapy in patients with diabetes mellitus: A non-comparative, open-label study," Clinical Drug Investigation, vol. 31, no. 6, pp. 427-434, 2011.

[6] R. Fogari, A. Mugellini, M. Circelli, and G. Cremonesi, "Combination delaprilmanidipine as antihypertensive therapy in highrisk patients," Clinical Drug Investigation, vol. 31, no. 7, pp. 439453, 2011.

[7] J. Mielcarek and O. Szamburska, "Inclusion complexes of manidipine with $\gamma$-cyclodextrin and identification of photodegradation products," Journal of Inclusion Phenomena, vol. 52, no. 3-4, pp. 195-200, 2005.

[8] K. Csabai, M. Vikmon, J. Szejtli, E. Redenti, G. Poli, and P. Ventura, "Complexation of manidipine with cyclodextrins and their derivatives," Journal of Inclusion Phenomena and Molecular Recognition in Chemistry, vol. 31, no. 2, pp. 169-178, 1998.
[9] J. Siepmann, R. A. Siegel, and M. J. Rathbone, Fundamentals and Applications of Controlled Release Drug Delivery, Springer, New York, NY, USA, 2012.

[10] M. Ahmad, A. Madni, M. Usman, A. Munir, N. Akhtar, and H. M. Shoaib Khan, "Pharmaceutical micro encapsulation technology for development of controlled release drug delivery systems," World Academy of Science, Engineering and Technology, vol. 75, pp. 384-387, 2011.

[11] D. T. Birnbaum and L. Brannon-Peppas, "Microparticle drug delivery systems," in Drug Delivery Systems in Cancer Therapy, pp. 117-135, Humana Press, Totowa, NJ, USA, 2004.

[12] K. Bowey and R. J. Neufeld, "Systemic and mucosal delivery of drugs within polymeric microparticles produced by spray drying," Biodrugs, vol. 24, no. 6, pp. 359-377, 2010.

[13] H. Yoshizawa, "Trends in microencapsulation research," Kona, vol. 22, pp. 23-31, 2004.

[14] R. P. Raffin, L. M. Colomé, E. E. S. Schapoval, D. S. Jornada, A. R. Pohlmann, and S. S. Guterres, "Gastro-resistant microparticles containing sodium pantoprazole: stability studies and in vivo anti-ulcer activity," Open Drug Delivery Journal, vol. 1, pp. 2835, 2007.

[15] S. K. Gosh, Functional Coatings by Polymer Microencapsulation, Wiley-VCH, Weinheim, Germany, 2006.

[16] S. V. Canevarolo Jr, Técnicas de Caracterização de Polímeros, Artliber, São Paulo, Brazil, 2004.

[17] A. Lamprecht, H. Rodero Torres, U. Schäfer, and C.-M. Lehr, "Biodegradable microparticles as a two-drug controlled release formulation: A potential treatment of inflammatory bowel disease," Journal of Controlled Release, vol. 69, no. 3, pp. 445454, 2000.

[18] Society of the Japanese Pharmacopoeia, The Japanese Pharmacopoeia, 16th, edition, supplement I, p. 1062, 2012.

[19] K. A. Khan, "The concept of dissolution efficiency," Journal of Pharmacy and Pharmacology, vol. 27, no. 1, pp. 48-49, 1975.

[20] G. Freitag, "Guidelines on dissolution profile comparison," Drug Information Journal, vol. 35, no. 3, pp. 865-874, 2001.

[21] R. C. R. Beck, A. R. Pohlmann, E. V. Benvenutti, T. D. Costa, and S. S. Guterres, "Nanostructure-coated diclofenac-loaded microparticles: Preparation, morphological characterization, in vitro release and in vivo gastrointestinal tolerance," Journal of the Brazilian Chemical Society, vol. 16, no. 6, pp. 1233-1240, 2005.

[22] S. R. Schaffazick, S. S. Guterres, L. L. Freitas, and A. R. Pohlmann, "Caracterização e estabilidade físico-química de sistemas poliméricos nanoparticulados para administração de fármacos," Química Nova, vol. 26, no. 5, pp. 726-737, 2003.

[23] P. V. Farago, R. P. Raffin, A. R. Pohlmann, S. S. Guterres, and S. F. Zawadzki, "Physicochemical characterization of a hydrophilic model drug-loaded PHBV microparticles obtained by the double emulsion/solvent evaporation technique," Journal of the Brazilian Chemical Society, vol. 19, no. 7, pp. 1298-1305, 2008.

[24] M. K. Riekes, F. M. Barboza, D. D. Vecchia et al., "Evaluation of oral carvedilol microparticles prepared by simple emulsion technique using poly(3-hydroxybutyrate-co-3hydroxyvalerate) and polycaprolactone as polymers," Materials Science and Engineering C, vol. 31, no. 5, pp. 962-968, 2011.

[25] M. P. Desai, V. Labhasetwar, G. L. Amidon, and R. J. Levy, "Gastrointestinal uptake of biodegradable microparticles: Effect of particle size," Pharmaceutical Research, vol. 13, no. 12, pp. 1838-1845, 1996. 
[26] F. S. Poletto, E. Jäger, M. I. Ré, S. S. Guterres, and A. R. Pohlmann, "Rate-modulating PHBHV/PCL microparticles containing weak acid model drugs," International Journal of Pharmaceutics, vol. 345, no. 1-2, pp. 70-80, 2007.

[27] J. B. E. Mendes, M. K. Riekes, V. M. Oliveira et al., "PHBV/PCL microparticles for controlled release of resveratrol: physicochemical characterization, antioxidant potential, and effect on hemolysis of human erythrocytes," The Scientific World Journal, vol. 2012, Article ID 542937, 13 pages, 2012. 

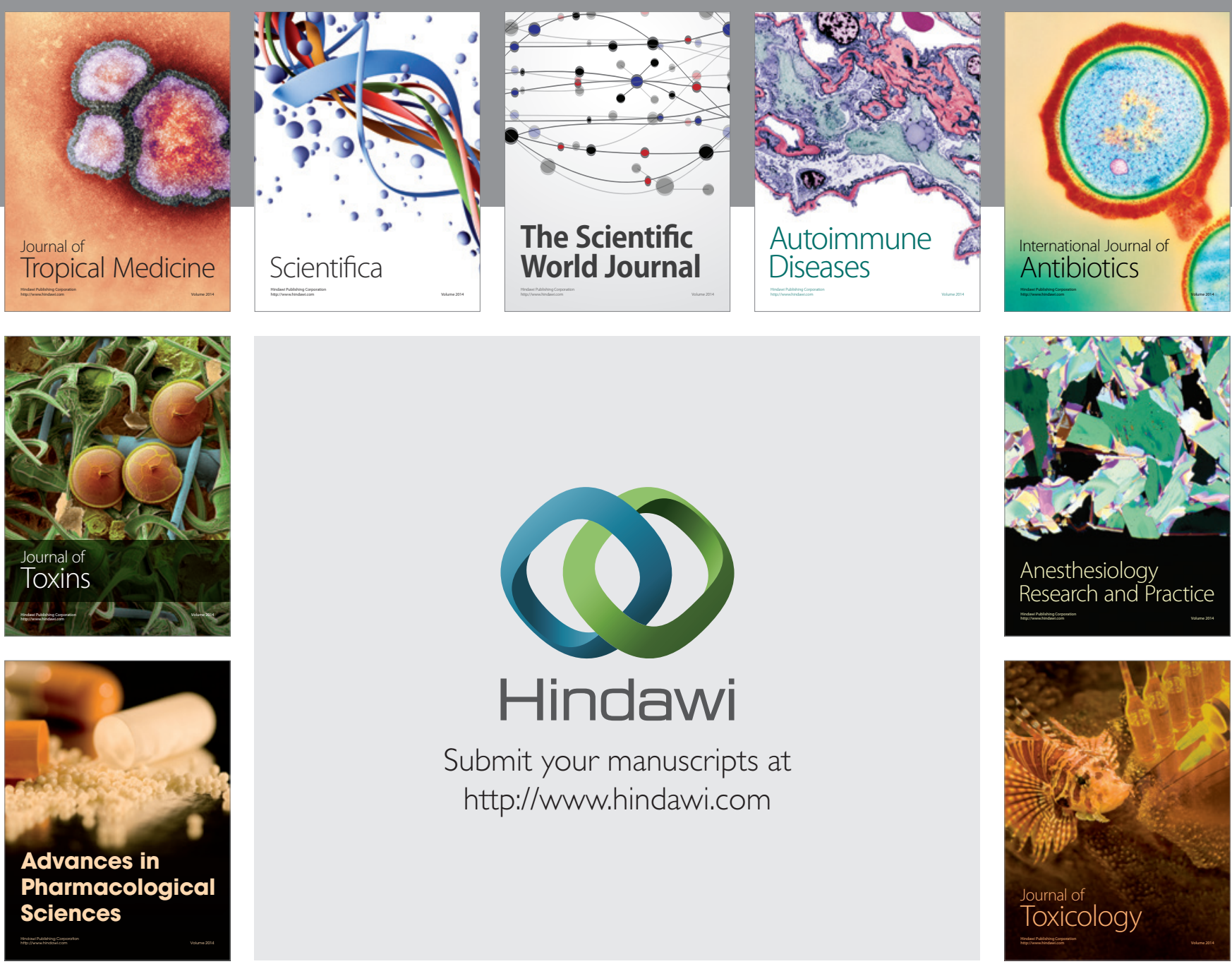

\section{Hindawi}

Submit your manuscripts at

http://www.hindawi.com
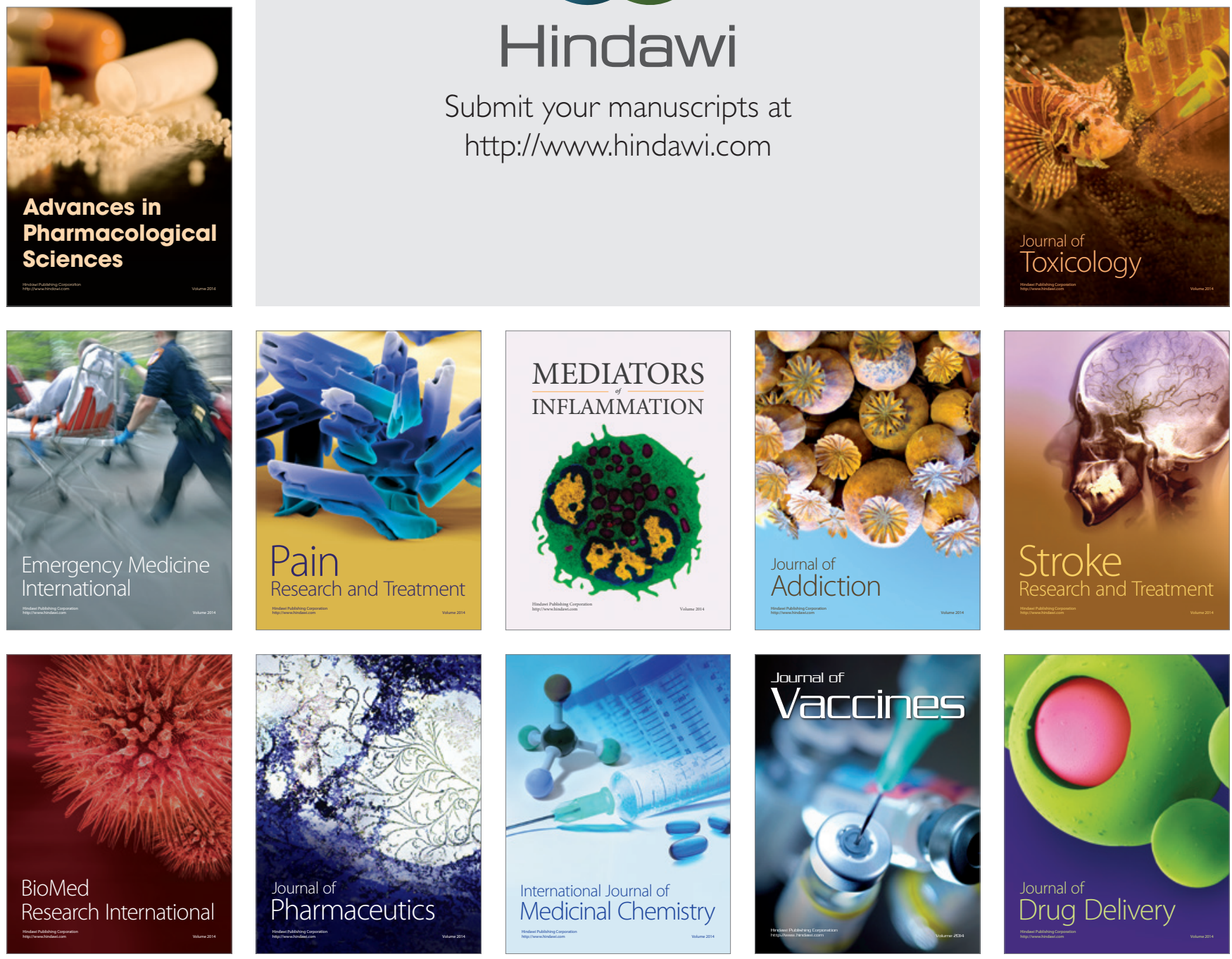